\title{
Patients' readiness to receive psychosocial care during nurse-led routine diabetes consultations in primary care: A mixed methods study
}

Citation for published version (APA):

van Dijk-de Vries, A., van Bokhoven, L., de Jong, S., Metsemakers, J. F. M., Verhaak, P. P. M., van der Weijden, T., \& van Eijk, J. T. M. (2016). Patients' readiness to receive psychosocial care during nurse-led routine diabetes consultations in primary care: A mixed methods study. International Journal of Nursing Studies, 63, 58-64. https://doi.org/10.1016/j.ijnurstu.2016.08.018

Document status and date:

Published: 01/11/2016

DOI:

10.1016/j.ijnurstu.2016.08.018

Document Version:

Publisher's PDF, also known as Version of record

\section{Document license:}

Taverne

Please check the document version of this publication:

- A submitted manuscript is the version of the article upon submission and before peer-review. There can be important differences between the submitted version and the official published version of record.

People interested in the research are advised to contact the author for the final version of the publication, or visit the DOI to the publisher's website.

- The final author version and the galley proof are versions of the publication after peer review.

- The final published version features the final layout of the paper including the volume, issue and page numbers.

Link to publication

\footnotetext{
General rights rights.

- You may freely distribute the URL identifying the publication in the public portal. please follow below link for the End User Agreement:

www.umlib.nl/taverne-license

Take down policy

If you believe that this document breaches copyright please contact us at:

repository@maastrichtuniversity.nl

providing details and we will investigate your claim.
}

Copyright and moral rights for the publications made accessible in the public portal are retained by the authors and/or other copyright owners and it is a condition of accessing publications that users recognise and abide by the legal requirements associated with these

- Users may download and print one copy of any publication from the public portal for the purpose of private study or research.

- You may not further distribute the material or use it for any profit-making activity or commercial gain

If the publication is distributed under the terms of Article 25fa of the Dutch Copyright Act, indicated by the "Taverne" license above, 


\title{
Patients' readiness to receive psychosocial care during nurse-led routine diabetes consultations in primary care: A mixed methods study ${ }^{\text {is }}$
}

\author{
Anneke van Dijk-de Vries ${ }^{\mathrm{a}, \mathrm{b}, *}$, Marloes A. van Bokhoven ${ }^{\mathrm{a}}$, Sabine de Jong ${ }^{\mathrm{a}}$, \\ Job F.M. Metsemakers ${ }^{\mathrm{a}}$, Peter F.M. Verhaak ${ }^{\mathrm{c}, \mathrm{d}}$, Trudy van der Weijden ${ }^{\mathrm{a}}$, \\ Jacques Th. M. van Eijk ${ }^{\mathrm{b}}$ \\ a Maastricht University, CAPHRI School for Public Health and Primary Care, Department of Family Medicine, Maastricht, The Netherlands \\ ${ }^{\mathrm{b}}$ Maastricht University, CAPHRI School for Public Health and Primary Care, Department of Social Medicine, Maastricht, The Netherlands \\ ${ }^{\mathrm{c}}$ Netherlands Institute of Health Services Research, Utrecht, The Netherlands \\ d Groningen University, University Medical Center Groningen, Department of General Practice, Groningen, The Netherlands
}

\section{A R T I C L E IN F O}

\section{Article history:}

Received 13 November 2015

Received in revised form 25 August 2016

Accepted 26 August 2016

\section{Keywords:}

Diabetes mellitus

Family practices

Mixed methods

Primary care nursing

Psychosocial

Self-management

\begin{abstract}
A B S T R A C T
Background: Patients with type 2 diabetes mellitus face several emotional and social consequences of their chronic illness in their everyday life. Symptoms of distress and depression are prevalent. For providing psychosocial self-management support, nurses in primary care were trained to identify patients with psychosocial problems during routine medically-shaped diabetes consultations. However, detection rates appeared to be strikingly low.

Objectives: Our study aimed to examine patients' readiness to discuss psychosocial problems with nurses during diabetes consultations.

Design: A mixed methods design was used in which qualitative data collection was followed up by quantitative data collection.

Setting: Diabetes care in a regional group of family practices in the south of the Netherlands.

Participants: Type 2 diabetes patients with psychosocial problems, determined by a self-administered questionnaire.

Methods: First, in-depth interviews $(\mathrm{n}=12)$ were conducted about patients' experiences with routine diabetes consultations and their perspective on a biopsychosocial care approach. Based on a qualitative content analysis, a structured questionnaire was designed to further explore the findings among a larger group of patients. This questionnaire was completed by 205 patients. The questionnaire included 14 items measuring patients' agreement with statements about diabetes care and the role of the nurse to focus on patients' emotional and social functioning.

Results: The interviews showed that patients view a diabetes consultation primarily as a biomedical check-up, and do not perceive discussion of psychosocial well-being as an integral part of diabetes management. More than $90 \%$ of the sample showed a positive attitude towards current diabetes consultations. Patients' intentions and perceived needs regarding a biopsychosocial care approach of the nurse were variable. Younger patients seemed more open to discussing psychosocial problems with the nurse than patients over 65. Patients' openness to discussing psychosocial problems was not significantly $(\mathrm{p}<0.05)$ associated with the nurses being trained in the biopsychosocial self-management approach. Conclusion: Patients see primary care nurses primarily as specialists regarding the biomedical management of diabetes. Although patients seemed to support the ideal of integrated care, they did
\end{abstract}

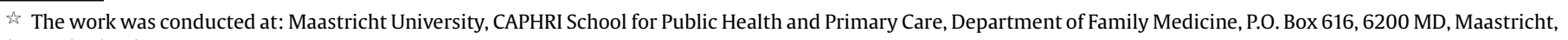
The Netherlands.

* Corresponding author.

E-mail addresses: anneke.vandijk@maastrichtuniversity.nl (A. van Dijk-de Vries), loes.vanbokhoven@maastrichtuniversity.nl (M.A. van Bokhoven), sabinedejong88@gmail.com (S. de Jong), job.metsemakers@maastrichtuniversity.nl (J.F.M. Metsemakers), p.verhaak@nivel.nl (P.F.M. Verhaak), trudy.vanderweijden@maastrichtuniversity.nl (T. van der Weijden), j.vaneijk@maastrichtuniversity.nl (J.T. M. van Eijk).
} 
not expect a discussion about psychosocial problems in diabetes consultations. The incorporation of systematic detection of patients with psychosocial problems in diabetes care requires endeavours to make patients acquainted with the new role of the nurse.

( 2016 Elsevier Ltd. All rights reserved.

What is already known about the paper?

- Self-management support is a key component of effective diabetes care.

- Nurses in the family practice can play a crucial role in promoting patients' self-management skills.

- The routine care for type 2 diabetes patients is primarily focused on biomedical self-management tasks.

\section{What this paper adds}

- Patients see a diabetes consultation primarily as a biomedical check-up, and don't expect a discussion about psychosocial issues with the practice nurse.

- Patients support the ideal of a biopsychosocial care approach of the practice nurse.

- Patients' expectations seem to be a vital factor for realizing biopsychosocial care.

\section{Introduction}

The transition from a largely acute care model into chronic care management for the increasing number of patients with chronic conditions changes the roles of health care professionals. Instead of prescribing medical interventions, the main focus shifts to a collaborative approach between health professionals and patients, aimed at supporting patients in acquiring the skills and confidence to manage their chronic conditions in their everyday lives (Bodenheimer et al., 2002). Evidence across multiple chronic conditions suggests that effective self-management support can improve patients' self-care behaviours, health outcomes and daily functioning (Barlow et al., 2002; Franek, 2013).

In scientific literature, the concept of self-management refers to patients' decisions and actions regarding the medical, emotional and role management tasks (Lorig and Holman, 2003). Such a biopsychosocial approach of self-management is also crucial in diabetes care. Patients with type 2 diabetes mellitus do not only face challenges in daily life with regard to medication and lifestyle issues. They may also experience emotions like anger, fear, frustration and depression (Pearce et al., 2013). Research has shown that symptoms of distress and depression are prevalent among diabetes patients (Pouwer, 2009). These emotional problems are associated with a negative impact on glycaemic control, adherence to treatment, complication rates and well-being (Egede and Ellis, 2010; Fisher et al., 2010). In addition to the medical and emotional self-management tasks, patients with chronic conditions have to create new, meaningful social roles (Lorig and Holman, 2003). Qualitative studies have illustrated the social demands imposed by diabetes, and the challenges of finding a balance between diabetes management and living a 'normal life' (Hinder and Greenhalgh, 2012; Townsend et al., 2006).

Patients with diabetes are increasingly monitored by nurses in the family practice. These nurses can play a crucial role in helping patients to engage in behaviours that affect their health in a positive way. However, studies in western countries show limited attention in chronic care consultations towards emotional and social consequences of chronic illness (Elissen et al., 2013; Mulder et al., 2015). Although systematic screening for psychological problems is recommended in international guidelines (IDF Clinical Guidelines Task Force, 2012), the primary focus of diabetes consultations is on somatic aspects, medication and lifestyle issues (Elissen et al., 2013).

In order to realise a shift towards a biopsychosocial approach in diabetes care, nurses in Dutch family medicine were taught to detect patients who perceived a burden of diabetes in their daily functioning and with symptoms of emotional distress, and to provide self-management support when needed. The number of patients who were detected by the nurses were strikingly small. This could be ascribed to limitations in the nurses' detection skills, but also to the extent to which the biopsychosocial approach met the needs of the patients. The need to further explore patients' perceptions as consumers of care is increasingly recognized in the literature since patient satisfaction has been linked to patient compliance and clinical outcomes. (Halcomb et al., 2013). Research showed that greater clarity around the role of the nurse may enhance the acceptability of a nurse-led intervention (Halcomb et al., 2013). In this regard, we questioned whether patients in our study were ready to disclose their emotional and social problems to the practice nurse as they may have been socialized 'into the role of passive subjects of surveillance' due to somatic-oriented consultations (Chew-Graham et al., 2013). Their awareness of the importance of self-management, and their own sense of responsibility seems to be low, at least according to health professionals (Raaijmakers et al., 2013).

This paper aims to improve our understanding of patients' readiness to discuss psychosocial issues with nurses in the context of a medically-shaped diabetes consultation. We formulated the following research question: How do patients experience their current diabetes care, and what are their perspectives on a biopsychosocial care approach delivered by nurses during routine diabetes consultations?

\section{Methods}

\subsection{Design of the study}

We used a mixed methods design (Greene et al., 1989) to obtain a comprehensive understanding of patients' perspectives on biopsychosocial diabetes care. The study used an exploratorysequential approach (Edmonds and Kennedy, 2013), in which qualitative data collection was followed up by quantitative data collection. First, in-depth interviews were conducted and analysed. The subsequent quantitative phase aimed to further explore associations between perspectives on diabetes care and patient characteristics among a larger group of patients. This mixed methods study was part of a larger research project that was aimed at implementation of biopsychosocial self-management support in routine diabetes care (Van Dijk-de Vries et al., 2013). This larger study included a process evaluation and a pragmatic clusterrandomized trial ('SMS trial') in which patients who received diabetes care from nurses trained in the biopsychosocial selfmanagement support approach were compared with patients who received usual care (Van Dijk-de Vries et al., 2015).

\subsection{Study setting}

The study has been conducted in the Dutch primary care setting, in which most patients with type 2 diabetes mellitus have quarterly consultations of $20-30 \mathrm{~min}$ with practice nurses in the 
family practice (Heiligers et al., 2012). These practice nurses monitor the care of patients with chronic diseases. They work under supervision of general practitioners (GPs), which means that they cannot refer patients or prescribe medicines without permission of a GP. The care is based on evidence-based guidelines, and on national guidelines regarding the content, organization and quality of integrated diabetes care (Netherlands Diabetes Federation, 2007; Rutten et al., 2013; Struijs et al., 2012).

A regional group of family practices in the south of the Netherlands implemented a nurse-led Self-Management Support (SMS) intervention in routine diabetes consultations. (Van Dijk-de Vries et al., 2013) SMS included both the detection and selfmanagement support of patients with psychosocial problems. To identify eligible patients, nurses verbally administered the Daily Functioning Thermometer, which is a VAS-scale measuring patients perceived burden of diabetes in daily life, and the Distress Screener (Braam et al., 2009; Van Dijk-de Vries et al., 2013). Patients with score $>4$ on the Daily Functioning Thermometer and score $>3$ on the Distress Screener were provided self-management support, based on problem solving and reattribution techniques.

\subsection{Methods 1: qualitative phase}

\subsubsection{Participants}

The qualitative phase of the study included diabetes patients who would be eligible for the nurse-led self-management support due to a perceived burden of diabetes in daily functioning and symptoms of emotional distress. We used a purposive sampling method. Patients were recruited from March till May 2012. We tried to achieve variation in terms of patients' age, sex and duration of diabetes. Some of the patients were detected by the nurses during routine consultations. If they showed interest, a trained interviewer (SJ) contacted them by means of an information letter and phone call. We also selected participants of the SMS trial with score $>4$ on the Daily Functioning Thermometer and score $>3$ on the Distress Screener at the 4-months follow-up measurement, but who were not detected by the nurses during the routine diabetes consultations. These patients were directly phoned by the interviewer to ask for participation in an interview.

\subsubsection{Data collection}

Twelve semi-structured in-depth interviews, which took $45 \mathrm{~min}$ on average, were conducted at the patients' homes. An interview guide was used to ensure that the following topics were discussed: patients' experienced burden of diabetes, their perspectives on diabetes consultations in general, and their attitudes towards psychosocial care provided by practice nurses. Prior to an interview, information was given about the objectives of the study. Participants gave oral informed consent for the audio-taped interview. They were assured that the interview data would be dealt with confidentially and that the practice nurse or GP would not be informed about the content of the interview. All interviews were transcribed verbatim.

\subsubsection{Data analysis}

The interviews were analysed using qualitative content analysis (Graneheim and Lundman, 2004). The first step consisted of reading the transcripts, after which a process of condensation and abstraction started. Codes were assigned to meaningful words or sentences of the participants. Two researchers (SJ and AD) coded the data independently. Coding discrepancies were discussed until consensus was reached. The next step was to look for connections between the codes. A process of reflection and discussion resulted in agreement about the way to sort the codes into categories. These categories were clustered into key themes that reflected the underlying meaning of the categories. Discussions in the research team took place after interviews 4, 8, 11 and 12. After the 11th interview, data saturation was reached as no new codes emerged from the data.

\subsection{Methods 2: quantitative phase}

\subsubsection{Data collection}

Based on the qualitative phase, a short questionnaire was developed to explore the findings among a larger group of patients. Statements were formulated which reflected the patients' perspective and covered all the categories that arose from the interviews. Statements were checked and fine-tuned by the members of the research team regarding the face validity of the questionnaire. This development process resulted in a 14-item questionnaire. We used 5-point Likert scales, with 1 indicating 'totally disagree' and 5 indicating 'totally agree', to measure agreement with these statements.

\subsubsection{Participants}

The questionnaire was distributed by mail among all participants of the SMS trial $(n=264)$. The participants had in common that they had all been found to have psychosocial problems, as their scores on the self-administered screening questionnaire at the start of the trial indicated a perceived burden of diabetes in daily functioning and symptoms of emotional distress. The questionnaire was added to the 12-months follow-up measurement.

\subsubsection{Data analysis}

The quantitative data were analysed using IBM SPSS Statistics version 21.0 for Windows (Corp, 2012). Descriptive statistics were used to describe the outcomes for each statement. For the purpose of subgroup analysis, we reduced the 14 -item questionnaire to a smaller subset of meaningful components by means of a principal component analysis with varimax rotation. Loadings above 0.50 were considered to be clearly related to the factor. We also used Cronbach's alpha as an indicator of the internal consistency of a factor. The process was iterated until a subset of items was obtained showing a consistent and interpretable factor structure. For each respondent, an individual scale score was obtained by calculating a mean score for the factor items. Missing values were imputed by the median of that item. Some items were reversecoded to ensure that a higher score could be interpreted as more openness towards psychosocial care. The results were presented as dichotomized scores (high/low mean composite score). Patients with predominantly low scores on a factor (mean score below 3 ) were allocated to the 'low group'. We used Pearson chi-square tests to test for differences in patients' composite score with regard to the training of practice nurses in SMS, patients' psychosocial problems at the time of measurement, sex, age, and duration of diabetes. The robustness of all findings was checked by means of linear regression analyses and independent $t$-tests.

\section{Results}

\subsection{Qualitative phase}

The five women and seven men who were interviewed were aged 51-81 years, with a mean age of 65 years (see Table 1 ). The mean time that had elapsed since they were diagnosed with diabetes was 11 years. The sample included patients from seven nurses. Six of nine patients who were invited by these nurses refused to participate due to lack of interest, lack of time, or not feeling comfortable with an interview. Two of the 11 patients who were approached directly by the interviewer refused to participate because of lack of time. 
Table 1

Characteristics of interview participants $(n=12)$.

\begin{tabular}{llll}
\hline Respondent & Sex & Age (years) & Duration of DM2 ${ }^{\text {a }}$ (years) \\
\hline 1 & F & 71 & 15 \\
2 & M & 72 & 13 \\
3 & F & 81 & 20 \\
4 & M & 66 & 36 \\
5 & M & 62 & 4 \\
6 & M & 53 & 6 \\
7 & F & 67 & 15 \\
8 & M & 70 & 2 \\
9 & M & 74 & 10 \\
10 & F & 51 & 5 \\
11 & F & 57 & 2 \\
12 & M & 62 & 3 \\
\hline
\end{tabular}

a Number of years after the diagnosis of diabetes mellitus.

According to our content analysis, the following themes will be addressed: the aims of routine diabetes consultations and how patients prepare themselves for consultations, their perceived emotional and social burden in daily functioning, and the patients' perspective on discussing these issues with nurses.

Participants regarded a diabetes consultation as a routine check-up for their diabetes. They described evaluation of biomedical measurements as the primary aim of these checkups. This was summarized by a respondent as follows: 'The blood sampling., what are the outcomes? That's just the key point of the consultation. And then ... afterwards asking some questions. About experiencing symptoms and about something that may be related to my diabetes. Just to talk with her for a moment about these issues.' Some especially liked to receive feedback on how well they were managing their disease. They appreciated getting advice regarding their diabetes management, thereby referring to biomedical parameters, medication and lifestyle issues. The extent to which participants prepared themselves for a consultation differed. Some said that they came to a routine check-up without preparation, while others drew up a list of specific questions beforehand. A few participants seemed to assume that the issues that can be discussed in diabetes consultations are restricted to diabetesrelated physical topics, as illustrated by the following quote: 'Recently I ordered a book about diabetes, and it mentioned erectile dysfunction and so on. I thought, well, they mention it, so it is okay to talk about this issue with her. I didn't know that, I wasn't aware that it could be related to diabetes.'

The nurses' interest in patients' general well-being was appreciated. Frequent visits and taking time for 'just a chat' were mentioned as facilitators of a good relationship with the nurse. None of the participants actively referred to a dialogue about the impact of diabetes on their daily functioning as a specific component of diabetes consultations. In this regard, some participants found it difficult anyway to define the burden of diabetes, since problems could also be ascribed to their physical condition in general, their age and/or another chronic condition. Patients with multimorbidity often regarded the other conditions as having more impact on their daily functioning than the diabetes. Participants were confronted with several kinds of psychosocial issues in their daily functioning, like worries about other people, financial problems or specific life-events. Worries about poor diabetes control were not mentioned during the interviews. A few participants referred to a possible negative influence of emotional distress on diabetes control, since the nurse had stressed this. 'When I have feelings like distress, sadness. She said, I need to talk about it, I need to tell my story. Because it affects the diabetes.'

The interviewer explicitly asked patients if they would appreciate a discussion of psychosocial problems during a diabetes consultation. The response of those who had experienced the self- management support by the practice nurse was positive. Other participants were surprised and wondered what they could expect, as illustrated by the following quote: 'What do you mean? What should I expect, that she can empathize with me, or something like that?' Some changed their attitude during the interview, from negative to positive, towards discussing psychosocial problems during the diabetes consultation with the practice nurse. 'I think I'd like to discuss that [concerns about erectile dysfunction] ... maybe with a doctor? I should raise the subject with the practice nurse, I think. I think I'd dare to talk about it, that you [the interviewer] were here and I spoke with you about it.'

Several barriers were mentioned regarding a discussion about psychosocial problems with a practice nurse. Some preferred to discuss mental health problems with their GP rather than the nurse. Several participants said that they do not easily share worries or do not want to burden others with their problems. Two participants stated their inability to discuss psychosocial problems in the presence of a third person (i.e. partner, relative). Two men with diabetes-related sexual problems reported barriers to mentioning the consequences of these sensitive issues to a female nurse. Direct questions regarding this subject would be helpful, they stated. Others confirmed the need to get direct and clear questions about their psychosocial well-being.

\subsection{Quantitative phase}

Based on the interview findings, 14 statements were formulated to reflect patients' perspective on a routine diabetes consultation and the role of the practice nurse therein (see Table 2). This questionnaire was completed by 223 participants of the SMS trial. We excluded ten patients who had participated in the qualitative phase of the study, due to the potential influence of the interview on their perspectives on diabetes care. Another eight patients were excluded due to missing values for more than half of the 14 items. Data analysis included 86 patients who had received care from nurses trained in SMS, and 119 patients of nurses not trained in SMS. Patients' demographic characteristics are summarized in Table 3.

The outcomes of the 14-item questionnaire are summarized in Table 2. Patients' perspectives on diabetes consultations were mainly positive. More than $90 \%$ of our sample valued being checked for general well-being regarding their diabetes, and reported that the nurse had provided valuable counselling on their daily functioning. About three quarters of the respondents would consider in advance what they were going to discuss during a consultation. Patients' beliefs about the purpose of diabetes consultations showed some variation. Forty-two percent of the respondents agreed that a diabetes consultation is only intended to discuss medical issues of diabetes, while $34 \%$ disagreed.

More than $90 \%$ of the patients agreed that their practice nurse takes enough time to listen during a consultation. Questions about the burden imposed by their diabetes on their daily functioning at each consultation should be asked by nurses, according to two thirds of the sample. However, the benefits of discussing psychosocial issues with a practice nurse are not clear for everyone. A number of 56 respondents (28\%) agreed that it is useless to discuss psychosocial issues with the practice nurse, as she cannot do anything about it. Nevertheless, half of these 56 respondents also stated that they would mention emotional problems to their practice nurses. Emotional problems would not be mentioned by $28 \%$ of the sample. Worries about poor diabetes control were recognized by $68 \%$ of the sample. Half of the respondents agreed that emotional problems negatively affected their diabetes management. With regard to discussing psychosocial issues, one third of the sample would prefer a discussion with their GP. Direct questions about emotional well-being asked by the 
Table 2

Outcomes on 14 statements to measure patients' expectations and attitude towards a psychosocial approach in routine diabetes consultations ( $\mathrm{n}=205$ ).

\begin{tabular}{|c|c|c|c|c|}
\hline \multicolumn{2}{|c|}{ Statement } & \multirow{2}{*}{$\frac{N}{205}$} & \multirow{2}{*}{$\frac{\text { Mean }^{\mathrm{a}}}{4.58}$} & \multirow{2}{*}{$\begin{array}{l}\text { SD } \\
0.693\end{array}$} \\
\hline 1 & A diabetes consultation is an important moment for me, as this is when I find out how my diabetes is developing. & & & \\
\hline 2 & My practice nurse provides good guidance on dealing with my diabetes every day. & 204 & 4.40 & 0.828 \\
\hline 3 & Before I go to the diabetes consultation, I think about the issues I want to discuss. & 205 & 3.94 & 0.948 \\
\hline $4^{\mathrm{b}}$ & A diabetes consultation is only intended for discussing issues that have to do with the physical consequences of diabetes. & 200 & 2.89 & 1.190 \\
\hline 5 & My practice nurse takes enough time to listen closely to what I have to say. & 201 & 4.38 & 0.697 \\
\hline 6 & Each diabetes consultation should include a question about the problems my diabetes is causing me in my everyday life. & 203 & 3.84 & 0.900 \\
\hline $7^{\mathrm{b}}$ & It's not much use discussing emotional problems with the diabetes nurse, as she is not in a position to do anything about them. & 203 & 3.21 & 1.181 \\
\hline 8 & I tell the practice nurse about it when I have emotional problems (such as gloominess, stress or loneliness). & 204 & 3.88 & 0.995 \\
\hline 9 & I worry about it if I can't sufficiently control my diabetes. & 204 & 3.76 & 0.950 \\
\hline 10 & I find it harder to sufficiently control my diabetes when I'm having emotional problems. & 204 & 3.46 & 0.954 \\
\hline $11^{\mathrm{b}}$ & When I'm feeling down, I'd rather discuss it with my GP than with the practice nurse. & 204 & 2.97 & 1.247 \\
\hline 12 & I would appreciate it if the practice nurse would take the initiative to ask me if I have any emotional problems. & 205 & 3.77 & 0.962 \\
\hline $13^{\mathrm{b}}$ & I find it hard to talk to the practice nurse about my worries and anxieties. & 202 & 3.22 & 1.168 \\
\hline 14 & I have enough relatives and friends around me to support me when I'm having a difficult time. & 203 & 3.79 & 1.019 \\
\hline
\end{tabular}

a Based on 5-point Likert scales, with 1 indicating totally disagree and 5 indicating totally agree.

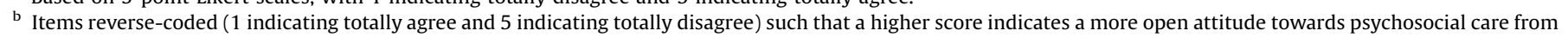
the practice nurse.

practice nurse would be appreciated by $67 \%$ of the respondents. Thirty percent reported that they found it difficult to share their worries and fears with the practice nurse. Regarding the availability of social support, $68 \%$ of our sample reported that they would get social support from family and friends when they experienced difficulties in their daily lives.

Based on the principal component analysis, in which items 1, 2 and 5 were not included as they were left-skewed, we identified one consistent composite variable of items 4, 7, 11 and 13 . This composite variable, with a Cronbach's alpha of 0.74 , was labelled 'Patients' attitude to discussing psychosocial problems in a diabetes consultation'. It represents patients' beliefs about the purpose of a diabetes consultation, difficulties of talking about emotional issues with the nurse, the extent to which patients preferred to receive psychosocial care from their GP, and their expectations of the nurses' support. A mean composite score below 3 , indicating a predominantly negative attitude, was found in 85 patients (42\%). Examination of the composite measure, as presented in Table 4, showed a significant association between age and patients' attitude $(\mathrm{p}<0.05)$. It indicates that patients aged 65 years or younger had a more positive attitude to discussing psychosocial issues during a diabetes consultation than patients older than 65 years. We found no statistically significant associations between patients' attitudes and whether or not their nurses had been trained in SMS. Furthermore, no significant associations were found with patients' current psychosocial problems, sex and time since diagnosis.

\section{Discussion}

The aim of the present study was to examine patients' readiness to discuss psychosocial issues with nurses in the context of a medically-shaped diabetes consultation. The two phases of our mixed methods approach yielded complementary results. Our qualitative findings emphasized that patients currently visit the practice nurse for the biomedical aspects of diabetes management and are not used to being questioned about psychosocial problems. The subsequent quantitative analysis indicated a positive attitude of patients towards the ideal of integrated care, i.e. attention for biomedical as well as emotional and social challenges in their everyday lives. Patients older than 65 years perceived more barriers to discussing psychosocial problems with the nurse than younger patients. Patients' attitudes appeared to be independent from their nurses having been trained in SMS or not.

Our study emphasized patients' expectations as a determining factor for successful integration of a biopsychosocial self-management approach in routine diabetes care. Since patients expect care for the biomedical aspects of diabetes, it challenges the acceptability of collaborative care initiatives in which mental health care is an integrated part of chronic care management (Bentley et al., 2016; Knowles et al., 2015). Other studies in the European primary care setting also indicate that patients expect a medical approach in routine consultations. For example, Swedish patients with diabetes, who were interviewed about the role of the nurse practitioner, expected advices regarding their medical management tasks. They did not report psychosocial aspects in this regard (Grund and Stomberg, 2012). A qualitative study in the UK found that patients with somatic chronic conditions did not expect their GPs to play a role in, or have the capacity to provide help with emotional problems in situations like bereavement or relationship breakdown (Alderson et al., 2014a).

Our findings agree with other studies that showed that patients' satisfaction with nurse-led care is high, and that patients value the nurses' clinical and medical knowledge (Jakimowicz et al., 2015; Laurant et al., 2005). According to a review of qualitative research, the approachability of a nurse, an informal environment, and the

Table 3

Demographic characteristics of patients participating in the questionnaire survey $(\mathrm{n}=205)$ Values are numbers (percentages) unless stated otherwise.

\begin{tabular}{|c|c|c|c|c|}
\hline Characteristic & & $\begin{array}{l}\text { Total } \\
(\mathrm{n}=205)\end{array}$ & $\begin{array}{l}\text { Patients of PNs trained in SMS } \\
(\mathrm{n}=86)\end{array}$ & $\begin{array}{l}\text { Patients of PNs not trained in SMS } \\
(\mathrm{n}=119)\end{array}$ \\
\hline Gender & Female & $98(47.8)$ & $42(48.8)$ & $56(47.1)$ \\
\hline Age & Mean age in years (SD) & $66(9.4)$ & $65(10.5)$ & $66(8.5)$ \\
\hline Duration of diabetes & Mean duration in years (SD) & $10.0(7.0)$ & $10.5(8.0)$ & $9.5(6.2)$ \\
\hline \multirow{4}{*}{$\begin{array}{l}\text { Highest level of } \\
\text { education }\end{array}$} & Primary school or pre-vocational education & $144(70.2)$ & $60(69.8)$ & $84(70.6)$ \\
\hline & Upper secondary general or vocational education & $40(19.5)$ & $19(22.1)$ & $21(17.6)$ \\
\hline & $\begin{array}{l}\text { Higher professional education or university } \\
\text { education }\end{array}$ & $14(6.8)$ & $4(4.7)$ & $10(8.4)$ \\
\hline & Missing & $7(3.4)$ & $3(3.5)$ & $4(3.4)$ \\
\hline
\end{tabular}


Table 4

Outcomes of Pearson chi-square test for the composite score 'Patients' attitude towards discussing psychosocial problems in a diabetes consultation'.

\begin{tabular}{|c|c|c|c|}
\hline & Number of patients & $\begin{array}{l}\text { \% with a } \\
\text { positive attitude towards discussing } \\
\text { psychosocial problems in a } \\
\text { diabetes consultation }\end{array}$ & P-value \\
\hline Type of diabetes care & & & 0.125 \\
\hline Nurses trained in SMS & 86 & $52 \%$ & \\
\hline Nurses not trained in SMS & 119 & $63 \%$ & \\
\hline Problems of daily emotional and social functioning ${ }^{a}$ & & & 0.694 \\
\hline Yes & 78 & $58 \%$ & \\
\hline No & 119 & $61 \%$ & \\
\hline Sex & & & 0.128 \\
\hline Male & 107 & $64 \%$ & \\
\hline Female & 98 & $53 \%$ & \\
\hline Age & & & 0.017 \\
\hline$\leq 65$ years & 95 & $67 \%$ & \\
\hline$>65$ years & 110 & $51 \%$ & \\
\hline Diagnosis of diabetes & & & 0.910 \\
\hline$\leq 5$ years ago & 59 & $60 \%$ & \\
\hline$>5$ years ago & 133 & $61 \%$ & \\
\hline
\end{tabular}

a At time of measurement, according to the screening criteria of the SMS study.

time that nurses spent to treat patients in an holistic manner are perceived to be helpful to be more open to a nurse (Jakimowicz et al., 2015). However, patients can be positive about the idea of case-finding for depression and at the same time do not feel that the chronic disease review is an obvious place for them to discuss mood issues (Alderson et al., 2014b). Another recent study found that patients preferred a separate space to discuss mental health problems (Knowles et al., 2015).

\subsection{Strengths and limitations}

The strength of our study is that we started with in-depth interviews to explore patients' experiences with current diabetes care and their perspectives on the role of the nurse in diabetes consultations, and further explored our findings by means of a structured questionnaire distributed among a larger sample consisting partly of patients who had been exposed to the psychosocial SMS approach and partly of patients who had not. The sample consisted of patients who perceived a burden of diabetes in daily functioning and emotional distress and/or had experienced these problems in the last year according to written screening outcomes. This screening was conducted in a diabetes population of more than 3500 patients, of whom $20 \%$ met the eligibility criteria for the self-management support (Van Dijk-de Vries et al., 2015). We believe that this was an adequate sample to further understand patients' readiness to discuss psychosocial issues in nurse-led medical encounters. There may have been some selection bias as participants had already responded on the screening questionnaire and thereafter gave informed consent for follow-up measurements. Patients who are open for participation in research might also be more open to question of the nurse about their psychosocial functioning.

In developing our questionnaire, we stayed close to the findings of the qualitative analysis to ensure that it would represent all facets that were found to be crucial regarding patients' readiness to discuss psychosocial issues in diabetes consultations. It was aimed to further explore our qualitative findings among a larger group of patients. We are aware that the development of a valid and reliable tool requires more rigorous steps. Consequently, the outcomes of the quantitative phase should be interpreted with caution.

Our quantitative analysis did not show significant differences between patients who received care from nurses trained in SMS compared to patients from non-trained nurses. This could be ascribed to problems with the integration of SMS into daily practice, as well as to the period of time that professionals and patients need to change their roles and expectations (Alderson et al., 2014b).

\subsection{Implications}

A requirement for successful integration of a biopsychosocial care approach in routine diabetes care is the identification of patients who need support in their emotional and social selfmanagement tasks. Given that patients were mainly positive about their current diabetes care in both parts of our study, it is unclear to what extent they perceive a need for systematic attention being given by a nurse to difficulties in their psychosocial functioning. One may question to what extent nurses should be involved in the detection of psychosocial problems during diabetes check-ups when patients do not take the initiative. However, monitoring of well-being during routine visits fits in with a holistic approach, which is in theory seen as inherent to the care approach of primary care providers (The Dutch College of General Practitioners (NHG), 2011). As we found in this study, a challenge is the exclusively disease-focused context in which detection of psychosocial problems for the purpose of providing self-management support needs to be integrated. It calls for socializing health professionals in an integrated care approach and changing the chronic care context in such a way that patients are informed and enabled to express psychosocial problems. Both professionals and patients will need time to get used to this integrated care approach. As our study suggests that not all patients with poor diabetes control feel inclined or even feel not interested to express psychosocial issues during a consultation, further research is needed on how patients who could benefit from a psychosocial self-management intervention can be identified during routine consultations.

\section{Conclusion}

Patients see their practice nurses as specialized biomedical diabetes managers. Their expectations regarding nurse-led diabetes consultations are particularly related to the biomedical aspects of diabetes. As a consequence, patients would not feel inclined to raise the subject of psychosocial problems, although they have a positive attitude towards an integrated care approach. A decision by policy makers, health insurers and health professionals to incorporate systematic detection of psychosocial problems in nurse-led diabetes consultations requires endeavours to inform patients and help them change their expectations and behaviours towards an integrated self-management approach. 


\section{Conflict of interest}

The authors have no competing interests to report.

\section{Acknowledgements}

We wish to thank all patients who participated in this study. We received funding from the Dutch Diabetes Research Foundation (Diabetes Fonds) under grant no. 2010.13.1366 (Voice of the Patient programme), and a financial contribution from the 'Annadal Foundation' in Maastricht, an independent financial support fund for healthcare.

The 'HOZL' group of collaborating family practices in the eastern part of the Southern Limburg region was involved in the SMSproject. During the project, CZ Health Insurance included a fee for SMS in the bundled payment arrangement for diabetes care.

\section{References}

Alderson, S., Foy, R., Glidewell, L., House, A., 2014a. Patients understanding of depression associated with chronic physical illness: a qualitative study. BMC Fam. Pract. 15 (1), 37. doi:http://dx.doi.org/10.1186/1471-2296-15-37.

Alderson, S.L., Russell, A.M., McLintock, K., Potrata, B., House, A., Foy, R., 2014b. Incentivised case finding for depression in patients with chronic heart disease and diabetes in primary care: an ethnographic study. BMJ Open 4 (8) doi:http:// dx.doi.org/10.1136/bmjopen-2014-005146.

Barlow, J., Wright, C., Sheasby, J., Turner, A., Hainsworth, J., 2002. Self-management approaches for people with chronic conditions: a review. Patient Educ. Couns. 48 (2), 177-187.

Bentley, M., Stirling, C., Robinson, A., Minstrell, M., 2016. The nurse practitionerclient therapeutic encounter: an integrative review of interaction in aged and primary care settings. J. Adv. Nurs. doi:http://dx.doi.org/10.1111/jan.12929.

Bodenheimer, T., Wagner, E.H., Grumbach, K., 2002. Improving primary care for patients with chronic illness. JAMA 288 (14), 1775-1779. doi:http://dx.doi.org/ 10.1001 /jama.288.14.1775

Braam, C., van Oostrom, S.H., Terluin, B., Vasse, R., De Vet, H.C.W., Anema, J.R., 2009. Validation study of a distress screener. J. Occup. Rehabil. 19 (3), 231-237.

Chew-Graham, C., Hunter, C., Langer, S., Stenhoff, A., Drinkwater, J., Guthrie, E., Salmon, P., 2013. How QOF is shaping primary care review consultations: a longitudinal qualitative study. BMC Fam. Pract.14 (1), 103. doi:http://dx.doi.org/ 10.1186/1471-2296-14-103.

I. Corp, 2012. IBM SPSS Statistics for Windows, Version 21.0. IBM Corp., Armonk, NY.

Edmonds, W.A., Kennedy, T.D., 2013. An Applied Reference Guide to Research Designs Quantitative, Qualitative and Mixed Methods. Sage, Thousand Oaks, CA.

Egede, L.E., Ellis, C., 2010. Diabetes and depression: global perspectives. Diabetes Res. Clin. Pract. 87 (3), 302-312. doi:http://dx.doi.org/10.1016/j.diabres.2010.01.024.

Elissen, A., Nolte, E., Knai, C., Brunn, M., Chevreul, K., Conklin, A., Durand-Zaleski, I., Erler, A., Flamm, M., Frolich, A., Fullerton, B., Jacobsen, R., Saz-Parkinson, Z Sarria-Santamera, A., Sonnichsen, A., Vrijhoef, H., 2013. Is Europe putting theory into practice? A qualitative study of the level of self-management support in chronic care management approaches. BMC Health Serv. Res. 13 (1), 117. doi: http://dx.doi.org/10.1186/1472-6963-13-117.

Fisher, L., Mullan, J.T., Arean, P., Glasgow, R.E., Hessler, D., Masharani, U., 2010. Diabetes distress but not clinical depression or depressive symptoms is associated with glycemic control in both cross-sectional and longitudinal analyses. Diabetes Care 33 (1), 23-28. doi:http://dx.doi.org/10.2337/dc09-1238.

Franek, J., 2013. Self-management support interventions for persons with chronic disease: an evidence-based analysis. Ont. Health Technol. Assess. Ser. 13 (9), 1 60 .

Graneheim, U.H., Lundman, B., 2004. Qualitative content analysis in nursing research: concepts, procedures and measures to achieve trustworthiness. Nurse Educ. Today 24 (2), 105-112. doi:http://dx.doi.org/10.1016/j.nedt.2003.10.001.

Greene, J.C., Caracelli, V.J., Graham, W.F., 1989. Toward a conceptual framework for mixed-method evaluation designs. Educ. Eval. Policy Anal. 11 (3), 255-274. doi: http://dx.doi.org/10.3102/01623737011003255.
Grund, J., Stomberg, M.W., 2012. Patients' expectations of the health advice conversation with the diabetes nurse practitioner. J. Prim. Care Community Health 3 (4), 230-234. doi:http://dx.doi.org/10.1177/2150131911435263.

Halcomb, E.J. Peters, K., Davies, D., 2013. A qualitative evaluation of New Zealand consumers perceptions of general practice nurses. BMC Fam. Pract. 14, 26. doi: http://dx.doi.org/10.1186/1471-2296-14-26.

Heiligers, P.J.M., Noordman, J., Korevaar, J.C., Dorsman, S., Hingstman, L., Dulmen, A. M.V., Bakker, D.H.D., 2012. Kennisvraag: praktijkondersteuners in de huisartspraktijk (POH's) klaar voor de toekomst? [Knowledge base: Practice nurses in the GP practices, ready for the future?]. Netherlands Institute for Health Services Research (NIVEL), Utrecht.

Hinder, S., Greenhalgh, T., 2012. This does my head in Ethnographic study of selfmanagement by people with diabetes. BMC Health Serv. Res. 12, 83. doi:http:// dx.doi.org/10.1186/1472-6963-12-83.

IDF Clinical Guidelines Task Force, 2012. Global Guideline for Type 2 Diabetes. International Diabetes Federation, Brussels.

Jakimowicz, S., Stirling, C., Duddle, M., 2015. An investigation of factors that impact patients' subjective experience of nurse-led clinics: a qualitative systematic review. J. Clin. Nurs. 24 (1-2), 19-33. doi:http://dx.doi.org/10.1111/jocn.12676.

Knowles, S.E., Chew-Graham, C., Adeyemi, I., Coupe, N., Coventry, P.A., 2015 Managing depression in people with multimorbidity: a qualitative evaluation of an integrated collaborative care model. BMC Fam. Pract. 16, 32. doi:http://dx. doi.org/10.1186/s12875-015-0246-5.

Laurant, M., Reeves, D., Hermens, R., Braspenning, J., Grol, R., Sibbald, B., 2005. Substitution of doctors by nurses in primary care. Cochrane Database Syst. Rev. 2, CD001271. doi:http://dx.doi.org/10.1002/14651858.cd001271.pub2.

Lorig, K.R., Holman, H., 2003. Self-management education: history, definition, outcomes, and mechanisms. Ann. Behav. Med. 26 (1), 1-7.

Mulder, B.C., van Belzen, M., Lokhorst, A.M., van Woerkum, C.M., 2015. Quality assessment of practice nurse communication with type 2 diabetes patients. Patient Educ. Couns. 98 (2), 156-161. doi:http://dx.doi.org/10.1016/j. pec.2014.11.006.

Netherlands Diabetes Federation, 2007. NDF care standard. Transparancy and Quality of Diabetes Care for People with Type 2 Diabetes. Netherlands Diabetes Federation (NDF), Amersfoort.

Pearce, M.J., Pereira, K., Davis, E., 2013. The psychological impact of diabetes: practical guide for the nurse practitioner. J. Am. Assoc. Nurse Pract. 25 (11), 578583. doi:http://dx.doi.org/10.1002/2327-6924.12035.

Pouwer, F., 2009. Should we screen for emotional distress in type 2 diabetes mellitus? Nat. Rev. Endocrinol. 5 (12), 665-671. doi:http://dx.doi.org/10.1038/ nrendo.2009.214.

Raaijmakers, L., Hamers, F., Martens, M., Bagchus, C., de Vries, N., Kremers, S., 2013. Perceived facilitators and barriers in diabetes care: a qualitative study among health care professionals in the Netherlands. BMC Fam. Pract. 14 (1), 114. doi: http://dx.doi.org/10.1186/1471-2296-14-114.

Rutten, G. De Grauw, W., Nijpels, G., Houweling S, Van de Laar, F, Bilo, H. Holleman, F., Burgers, J., Wiersma, T., PGH, J., 2013. NHG-standaard diabetes mellitus type 2 (derde herziening) [NHG practice guideline diabetes mellitus type 2 (Third revision)]. Huisarts Wet. 56 (10), 512-525.

Struijs, J., de Jong-van Til, J., Lemmens, L., Drewes, H., De Bruin, S., Baan, C., 2012 Bundled Payments of Diabetes Care: Effects on Care Delivery Process and Quality of Care at Three-year Follow-up. National Institute for Public Health and the Environment (RIVM), Bilthoven.

The Dutch College of General Practitioners (NHG), 2011. Core Values of General Practice/Family Medicine. Position Paper. The Dutch College of General Practitioners (NHG), Utrecht.

Townsend, A., Wyke, S., Hunt, K., 2006. Self-managing and managing self: practical and moral dilemmas in accounts of living with chronic illness. Chronic Illn. 2 (3), 185-194. doi:http://dx.doi.org/10.1177/17423953060020031301.

Van Dijk-de Vries, A., Van Bokhoven, M., Terluin, B., Van der Weijden, T., Van Eijk, J.T. M., 2013. Integrating nurse-led Self-Management Support (SMS) in routine primary care: design of a hybrid effectiveness-implementation study among type 2 diabetes patients with problems of daily functioning and emotional distress: a study protocol. BMC Fam. Pract. 14, 77. doi:http://dx.doi.org/10.1186/ 1471-2296-14-77.

Van Dijk-de Vries, A., Van Bokhoven, M.A., Winkens, B., Terluin, B., Knottnerus, J.A. Van der Weijden, T., Van Eijk, J.T.M., 2015. Lessons learnt from a clusterrandomised trial evaluating the effectiveness of Self-Management Support (SMS) delivered by practice nurses in routine diabetes care. BMJ Open 5 (6) doi: http://dx.doi.org/10.1136/bmjopen-2014-007014. 